\title{
Reconstrução facial como um meio de identificação na odontologia legal: revisão de
}

\section{literatura}

\author{
Facial reconstruction as a means of identification in legal dentistry: literature review \\ La reconstrucción facial como medio de identificación en odontología jurídica: revisión de la
}

\section{literatura}

Géssyca Luyse Procópio Gonzaga ORCID: https://orcid.org/0000-0003-2111-5459 Centro Universitário Cesmac, Brasil E-mail: g.luyse@hotmail.com

Ana Beatriz Macêdo Fonseca

ORCID: https://orcid.org/0000-0002-1315-8849 Centro Universitário Cesmac, Brasil E-mail: anab.macedof@gmail.com Rita de Cássia Pereira Silva

ORCID: https://orcid.org/0000-0003-3919-8213 Centro Universitário Cesmac, Brasil E-mail: nicassiapereira@gmail.com Mariana dos Santos Bezerra

ORCID: https://orcid.org/0000-0003-4887-3356 Centro Universitário Cesmac, Brasil E-mail: marianasantosb@hotmail.com

Mayane Karyne Amâncio da Silva ORCID: https://orcid.org/0000-0001-7371-8812 Centro Universitário Cesmac, Brasil E-mail: mk-amancio@hotmail.com

Islyane de Albuquerque Santos ORCID: https://orcid.org/0000-0003-4223-4123 Centro Universitário Cesmac, Brasil

E-mail: islyane_albuquerque@hotmail.com

Lara Beatriz de Moraes Santos ORCID: https://orcid.org/0000-0002-3674-8374 Centro Universitário Cesmac, Brasil E-mail: larabeatrizms7@gmail.com

Livia Acioli Murta Torres

ORCID: https://orcid.org/0000-0001-8773-0337 Centro Universitário Cesmac, Brasil E-mail: livacyoli@hotmail.com

Andreza de Albuquerque Araújo ORCID: https://orcid.org/0000-0001-7149-6558 Centro Universitário Cesmac, Brasil

E-mail: albuquerqueandreza200@gmail.com

Thaís da Silva Vieira

ORCID: https://orcid.org/0000-0001-5022-7738 Centro Universitário Cesmac, Brasil E-mail: thais.kiyo@gmail.com

Kevan Guilherme Nóbrega Barbosa ORCID: https://orcid.org/0000-0002-9410-7356 Centro Universitario Cesmac, Brasil E-mail: kevanguilherme@gmail.com

\section{Resumo}

Objetivo: conhecer a atuação da odontologia legal para identificação humana, através da reconstrução facial forense, assim como, as diferentes técnicas empregadas e os principais recursos odontológicos utilizados neste processo. Metodologia: foi realizada uma revisão narrativa da literatura. Foram utilizados os descritores odontologia legal, reconstrução facial e antropologia forense. Revisão de literatura: A aplicação dos métodos de identificação humana é uma necessidade no contexto do trabalho dos Institutos Médico-legais. O trabalho pericial para a determinação da identidade de um cadáver é um desafio, especialmente quando este está parcialmente destruído como nos casos de corpos desmembrados, desfigurados, esqueletizados, carbonizados, vítimas de desastre de massa, putrefeitos, entre outros. Considerações finais: A Odontologia Forense apresenta uma função significativa no método de identificação, 
tornando-se segura e de fundamental relevância, uma vez que, a identificação e um recurso que precisa estar introduzido no cenário da Perícia Médico Legal e Odontológica, contribuindo com a justiça de forma efetiva para uma identificação eficaz.

Palavras-chave: Odontologia legal; Reconstrução facial; Antropologia forense.

\begin{abstract}
Objective: to know the role of legal dentistry for human identification, through forensic facial reconstruction, as well as the different techniques used and the main dental resources used in this process. Methodology: A narrative review of the literature was carried out. The descriptors forensic dentistry, facial reconstruction and forensic anthropology were used. Literature review: The application of human identification methods is a necessity in the context of the work of Medico-Legal Institutes. The forensic work to determine the identity of a corpse is a challenge, especially when it is partially destroyed, as in the cases of dismembered, disfigured, skeletonized, charred bodies, victims of mass disaster, putrefied, among others. Final considerations: Forensic Dentistry has a significant role in the identification method, making it safe and of fundamental importance, since identification is a resource that needs to be introduced in the Forensic and Dental Expertise scenario, contributing to justice effectively for effective identification.
\end{abstract}

Keywords: Forensic dentistry; Facial reconstruction; Forensic anthropology.

\title{
Resumen
}

Objetivo: conocer el papel de la odontología legal para la identificación humana, a través de la reconstrucción facial forense, así como las diferentes técnicas empleadas y los principales recursos dentales utilizados en este proceso. Metodología: Se realizó una revisión narrativa de la literatura. Se utilizaron los descriptores odontología forense, reconstrucción facial y antropología forense. Revisión de la literatura: La aplicación de métodos de identificación humana es una necesidad en el contexto del trabajo de los Institutos Médico-Legales. El trabajo pericial para determinar la identidad de un cadáver es un desafío, especialmente cuando está parcialmente destruido, como en los casos de cuerpos desmembrados, desfigurados, esqueletizados, carbonizados, víctimas de desastres masivos, putrefactos, entre otros. Consideraciones finales: La Odontología Forense tiene un rol significativo en el método de identificación, haciéndolo seguro y de fundamental importancia, ya que la identificación es un recurso que debe ser introducido en el escenario de la Medicina Forense y la Odontología, contribuyendo a la justicia de manera efectiva para una identificación efectiva.

Palabras clave: Odontología forense; Reconstrucción facial; Antropología Forense.

\section{Introdução}

A identidade pode ser conceituada como "conjunto de caracteres físicos, funcionais e psíquicos, natos ou adquiridos, porém permanentes, que torna uma pessoa diferente das demais e idêntica a si própria” (Vanrell, 2009).

A identificação, por outro lado, é "o processo pelo qual se determina a identidade". A preocupação com a identificação é bastante antiga. Atualmente, as relações sociais ou exigências civis, penais, administrativas e comerciais necessitam de sua comprovação (França, 2008).

A necessidade da identificação humana é fato incontroverso. Desde cedo, nas relações sociais, as pessoas precisam ser individualizadas. Entre vivos, é natural que os indivíduos, ao se conhecerem, de imediato se identifiquem, ao menos apresentando seus nomes. Dependendo da relação a ser estabelecida, outras informações são solicitadas e/ou fornecidas (Fernandes, 2010).

No caso de mortos, o estabelecimento de sua identidade é fundamental, por diversas razões, sejam de ordem familiar, emocional, social ou jurídica. Quando a identidade, por algum motivo, não puder ser determinada, lançam-se mão de métodos de identificação, desde que haja um suspeito. Isto ocorre porque é necessária a comparação de determinados parâmetros encontrados no cadáver (como impressões digitais, informações odontológicas ou DNA), denominados post-mortem, com os mesmos parâmetros da suposta vítima em vida, denominados ante-mortem (Fernandes, 2010).

A reconstrução facial forense não constitui método científico de identificação, mas sim instrumento que pode proporcionar o reconhecimento de um sujeito. Uma vez reconhecido, e então, havendo uma suposta vítima, será possível o emprego de métodos de identificação e o estabelecimento (ou não) da identidade do cadáver (Fernandes, 2010).

A técnica da Reconstrução Facial Forense (RFF) pode ser útil quando há pouca ou nenhuma evidência para a identificação humana, caracterizando-se como um método auxiliar neste processo (Pereira et al., 2017). A atuação do 
cirurgião-dentista no âmbito forense é amparada pela legislação federal competente, a Lei ${ }^{\circ} 5.081 / 66$, que regulamenta o exercício da odontologia no território brasileiro (Brasil; Musse, 2015).

Apesar da introdução da análise do DNA na identificação de restos humanos, muitos casos permanecem não identificados. Aproximadamente $10 \%$ dos cadáveres desconhecidos não podem ser identificados por meio de dados odontológicos ou outros métodos. Somente em 2003, na Suécia, sete pessoas não foram identificadas, e o aumento do turismo na Europa levará a mais descobertas de corpos de estrangeiros naquele país. Nestes casos, informações médicas e odontológicas normalmente não estão disponíveis para o processo de identificação (Andersson et al., 2005).

A maior parte dos métodos de identificação, como datiloscopia e análise de DNA, baseiam-se na comparação de dados ante-mortem e post-mortem. Não obstante, os dados ante-mortem não estão sempre disponíveis, e os dados post-mortem utilizáveis nem sempre são suficientes. Assim, a reconstrução facial é empregada como a derradeira possibilidade na busca da identidade de uma pessoa, quando outros métodos falharam ou não puderam ser aplicados (Vermeulen, 2005).

O estudo de características antropométricas é de importância fundamental na solução de problemas relacionados à identificação. As características craniométricas estão incluídas entre estas características, que estão proximamente conectadas à Odontologia Legal, pois podem ser utilizadas para auxiliar na identificação de um indivíduo a partir de um crânio (Rocha et al., 2003).

A identificação humana é uma atividade pericial que pode ser realizada no âmbito da Antropologia Forense por meio de diferentes técnicas. Neste sentido, a reconstrução facial corresponde a importante recurso, pois possibilita a reprodução de características perdidas ou desconhecidas de um indivíduo, com vistas ao reconhecimento do mesmo, contribuindo para sua identificação (De Paiva et al., 2005).

Shahrom et al. (1996) afirmam que o objetivo da realização de uma reconstrução facial forense é veicular ao público a existência de um indivíduo não identificado, na esperança de que um familiar ou amigo próximo do morto possa surgir com informações e dados ante-mortem para comparação e identificação. Os autores ressaltam que uma reconstrução facial não corresponde a uma fotografia do indivíduo enquanto vivo, mas pode ser considerada bem sucedida se for suficientemente realista para produzir uma boa resposta do público, levando à identificação do sujeito.

A Reconstrução Facial Forense (RFF) pode ser 2D ou 3D. Esta pode ser realizada de forma manual - RFF Plástica ou Manual, ou por meio do computador - RFF Digital ou Computadorizada (Matos et al., 2012).

Na técnica manual, a reconstrução é feita através da modelagem com argila ou outro material similar, exigindo do operador, além de conhecimento técnico, também destreza manual e, por outro lado, essa modalidade permite um viés subjetivo, a depender da interpretação e experiência do operador e a modelagem manual atualmente ainda é a técnica mais usada na reconstrução facial (Pereira et al., 2017).

Na técnica digital são utilizados softwares que processam imagens de fotografias ou tomografias do crânio e permitem a inserção dos planos musculares e pele. Nessa modalidade, há uma melhor qualidade na reprodução das características, tornando a face mais realista, isso porque reduz-se a percepção subjetiva do operador (Pereira et al., 2017).

Seja pela técnica manual ou digital, o resultado final da Reconstrução Facial Forense (RFF) não é a total precisão do rosto, mas uma aproximação que levará ao reconhecimento do sujeito pois, após a realização da Reconstrução Facial Forense (RFF), essa face pode ser veiculada em meios de comunicação, sendo factível o reconhecimento por algum familiar ou conhecido, existindo um suspeito, é possível prosseguir às análises convencionais para o estabelecimento ou não da identidade (Fernandes, 2010).

A identificação busca por elementos que permite a individualização de um indivíduo, ao comparar características que sejam coincidentes entre os dados ante-mortem e post-mortem. Por tanto, a face é um dos veículos mais importantes que carregam informações individuais. Afinal, as pessoas usam a face como um meio de reconhecer indivíduos todos os dias. 
Assim, a odontologia forense ou legal, através da reconstrução facial, atua no processo de identificação dos cadáveres, sendo capazes de determinar a origem dos restos mortais e ajudam a identificar vítimas de acidentes, homicídios, guerras ou desastres.

O objetivo do presente trabalho é conhecer a atuação da odontologia legal para identificação humana, através da reconstrução facial forense, assim como, as diferentes técnicas empregadas e os principais recursos odontológicos utilizados neste processo.

\section{Metodologia}

Para o desenvolvimento deste trabalho foi realizada uma revisão narrativa da literatura, sendo realizada entre os períodos de 1996 a 2020. Onde foram utilizadas publicações que tivessem como assunto principal reconstrução facial e odontologia legal, pela possibilidade de inclusão de um número maior de artigos, visto que se constatou, que o tema ainda tem sido pouco estudado. Além disso, incluíram-se publicações disponibilizados na íntegra na língua portuguesa e inglesa, e trabalhos de conclusão de curso.

Para realizar este levantamento bibliográfico incluiu pesquisa em bases eletrônicas e busca manual de citações nas publicações inicialmente identificadas. As bases eletrônicas pesquisadas foram literatura internacional em Ciências da Saúde (MEDLINE), Scientific Electronic Library Online (SciELO) e Biblioteca Virtual em Saúde do Ministério da Saúde (BVS). Foram utilizados os descritores odontologia legal, reconstrução facial e antropologia forense.

\section{Revisão de Literatura}

A odontologia forense possui três grandes áreas de atuação, sendo elas o diagnóstico e exame terapêutico de evoluções de lesões nos arcos superiores e inferiores; a identificação de indivíduos, especialmente em desastres em massa e investigações criminais; e a identificação através das marcas de mordidas que acontecem com frequência em agressões sexuais, casos de defesa pessoal e abusos (Debnath et al., 2016).

Nas décadas passadas a Odontologia Legal apresentava credibilidade contestável, porém, no cenário atual, a Odontologia Legal vem se consolidando através de avanços científicos de serviços prestados a saúde. Devido a quantidade de desastres e adversidades ocorrentes, assim, existindo a necessidade do exercício de uma equipe multidisciplinar (Vanrell; Borborema, 2007).

O reconhecimento de cadáveres humanos usualmente é realizado por parentes próximos ou conhecidos que reconhecem a aparência facial destes. Em determinados casos, a decomposição post mortem ou os danos expressivos às características faciais podem tornar o reconhecimento impraticável. A perda das características fisionômicas do indivíduo, pode ocorrer de forma natural ou proposital e estas perdas impossibilitam a identificação por métodos tradicionais (Whittaker, 1994).

Em desastres em massa, naturais ou resultados de intervenções humanas, em que as identificações por métodos tradicionais são comprometidas, as análises odontológicas se apresentam com grande importância. A análise da arcada dentária possibilita a obtenção de dados como espécie, ancestralidade, sexo, altura e idade dos indivíduos, além da análise de procedimentos odontológicos realizados ante mortem e anormalidades morfológicas, de extrema importância no auxílio da identificação post mortem. A diferenciação morfológica entre homens e mulheres através de análise craniométrica e a comparação de rugosidades palatinas a próteses dentárias são metodologias também empregadas na rotina do odontolegista (Croce; Júnior, 2012).

O processo de identificação pela Odontologia Legal deve ser subdividido em três subprocessos que serão efetuados por três equipes distintas: a) Equipe post - mortem (PM) - busca, coleta e documentação de informações por meio de exame 
dos corpos e descrição detalhada do crânio e cavidade bucal, realizada por odontolegistas da equipe PM; b) Equipe ante mortem (AM) - busca, coleta e uniformização de dados odontológicos das vítimas quando em vida, junto aos familiares, o qual servirá para o confronto com os dados PM, realizada pelos odontolegistas da equipe AM; c) Equipes de confronto - avaliação e combinação das informações AM e PM, realizada por odontolegistas da equipe de comparação (Brasil, 2015).

A identificação humana na Odontologia Forense é realizada através de análises comparativas e reconstrutivas (Queiroz, 2017). É necessário destacar que, quando os profissionais avaliam as características sexuais, não é o gênero que estão considerando, e sim o sexo biológico (Schall et al., 2020). Como conjectura da "identidade" tem os que dois indivíduos não são exatamente iguais em todas as suas características mensuráveis, mesmo gêmeos geneticamente idênticos (monozigóticos) diferem em alguns aspectos. Essas características tendem a sofrer mudanças em vários graus, desde o nascimento até a morte, na saúde e na doença, e, desde o desenvolvimento do esqueleto é influenciada por uma série de fatores que produzem diferenças nas proporções esqueléticas entre diferentes áreas geográficas, sendo desejável desenvolver meios de quantificar as variações que tais características apresentam (Krishan, 2007).

As características físicas dos seres humanos, ósseas ou tegumentares, apresentam grande variabilidade, influenciadas por fatores como hábitos alimentares, idade e aspectos geográficos sem, entretanto constituírem ou delimitarem uma raça diversa da humana ou mesmo umaetnia. Estudos relacionados às diferenças no crescimento e desenvolvimento craniofacial têm dividido, apenas didaticamente, os grupamentos humanos em três tipos: caucasoides, mongolóides e negróides. As características fisionômicas baseadas nesses grupos expressam-se com significância na largura da base nasal e espessura dos lábios (Silva, 2006).

Pereira et al. (2005) realizaram um estudo comparativo inter-raças e gêneros em indivíduos com harmonia facial através de radiografias cefalométricas de 80 brasileiros, divididos em dois grupos de 40, de acordo com as "raças branca e negra", cada um deles com 20 indivíduos de cada gênero com objetivo de estabelecer correlações entre as dimensões cefalométricas angulares. Os autores concluíram que não houve diferença estatisticamente significante na comparação das médias das medidas angulares, para os gêneros masculino e feminino, nos indivíduos de raça branca e negra.

A aplicação dos métodos de identificação humana é uma necessidade no contexto do trabalho dos Institutos Médicolegais. O trabalho pericial para a determinação da identidade de um cadáver é um desafio, especialmente quando este está parcialmente destruído como nos casos de corpos desmembrados, desfigurados, esqueletizados, carbonizados, vítimas de desastre de massa, putrefeitos, entre outros. Quando esses corpos são encontrados já em avançado estado de decomposição e não temos uma indicação da identidade da pessoa desaparecida correspondente, não teremos informações intra-vitae para comparação, o que impossibilita a aplicação dos protocolos preconizados pelo Guia DVI (Disaster Victims Identification) da Interpol, necropapiloscopia, odontologia forense e genética (Biancalana et al., 2005). Assim, a reconstrução facial forense (RFF) é uma opção, desde que, o crânio esteja presente.

O desenvolvimento da morfologia facial é influenciado por processos de crescimento do esqueleto craniofacial e nos elementos sobrejacente cartilaginoso, muscular e adiposo. Estes tecidos são diferencialmente influenciados por processos de crescimento (Simpson et al., 2002).

A craniometria é uma área que estuda os pontos de referência em crânios humanos, que são utilizados como meios de identificação e reconstrução facial utilizando o crânio humano como base para reconstrução quando outros meios não são disponíveis, incluindo determinadas características que são difíceis de serem encontradas ou caracterizadas sem os tecidos moles (Herrera, 2015).

O estudo detalhado da cabeça humana, constituída por 22 ossos e 32 elementos dentários possibilita que o odontolegista identifique o indivíduo. Através destas análises é possível em diversas situações determinar o sexo, 
ancestralidade, idade, estatura e também traçar o aspecto facial do indivíduo em vida através da técnica de reconstrução facial (Velho et al., 2012).

A determinação do sexo é um dos primeiros processos durante a identificação, pois é possível guiar o perito durante a identificação. Ela é realizada através da craniometria, uma das asas da antropologia humana cujo objetivo é estudar todas as características do crânio, tornando possível determinar as variáveis formas, tamanhos do neurocrânio e viscerocrânio, além da possibilidade de determinar a idade, raça e parentesco do indivíduo (Cabral, 2019).

A determinação do sexo durante a investigação forense é um dos protocolos antropológicos aderidos, ela é feita realizando uma avaliação métrica e visual do crânio e da pelve, e conforme a quantidade de informações presentes no laudo, o resultado que for obtido terá uma maior relevância na identificação. O crânio masculino, de maneira geral, é mais grosso e áspero de maneira geral em comparação com o crânio feminino. Além dessas estruturas, pode ser somada a essas informações a glabela, o rebordo orbitário, o arco zigomático, dentre outros (Almeida et al., 2015).

\section{Conclusão}

Os cirurgiões dentistas possuem conhecimento médico e antropológico geral no reconhecimento de partes do corpo, bem como as competências anatômicas odontológicas especializadas. A Odontologia Forense apresenta uma função significativa no método de identificação, tornando-se segura e de fundamental relevância, uma vez que, a identificação e um recurso que precisa estar introduzido no cenário da Perícia Médico Legal e Odontológica, contribuindo com a justiça de forma efetiva para uma identificação eficaz.

\section{Referências}

Almeida, S. M. de, Delwing, F., Azevedo, J. A. P. de, Nogueira, R. K. T., Falcão, F. P., \& Carvalho, S. P. M. (2015). Efetividade da documentação odontológica na identificação humana. RGO.Revista Gaúcha de Odontologia (Online), 63(4), 502-506. http://revodonto.bvsalud.org/scielo.php?script=sci_abstract\&pid=S198186372015000400021\&lng=p\&nrm=iso\&tlng=pt

Andersson, B., \& Valfridsson, M. (2005). Digital 3D Facial Reconstruction Based on Computed Tomography. https://www.divaportal.org/smash/get/diva2:20204/FULLTEXT01.pdf

Anthropometry in Forensic Medicine and Forensic Science. "Forensic Anthropometry." (2007). The Internet Journal of Forensic Science, 2(1). https://doi.org/10.5580/1dce

Biancalana, R. C., Vieira, M. G. D. M., Figueiredo, B. M. de J., Vicente, S. A. de F., Dezem, T. U., \& Silva, R. H. A. da. (2015). Desastres em massa: a utilização do protocolo de dvi da interpol pela odontologia legal. Revista Brasileira de Odontologia Legal, 2(2). https://doi.org/10.21117/rbol.v2i2.38

Brasil, J. de Â. C., \& Musse, J. de O. (2015). Caracterização da perícia odontolegal em instituto médico legal do interior da bahia. Revista Brasileira de Odontologia Legal, 2(2). https://doi.org/10.21117/rbol.v2i2.37

Brasil. (2015). Ministério da Justiça. Manual de Procedimentos em Odontologia para Identificação de Vítimas de Desastre. Departamento de Polícia Federal e Secretaria Extraordinária de Segurança para Grandes Eventos. Brasília. https://img1.wsimg.com/blobby/go/6151acb2-1fb5-499b-b966ddc51342c19b/downloads/Manual\%20de\%20Procedimentos\%20de\%20Odontologia\%20para\%20Id.pdf?ver=1614857749069

Cabral, R. (n.d.). Departamento de biologia bacharelado em ciências biológicas craniometria na identificação do sexo em esqueletos humanos -revisão de literatura. https://www.repository.ufrpe.br/bitstream/123456789/1997/1/tcc_rodrigocordeirocabral.pdf

Debnath, N. et al. (2016). Forensic odontology. Journal of Medical Society, v. 30, n. 1, p. 20.

Delton Croce, \& Delton Croce Júnior. (2012). Manual de medicina legal. Saraiva. p. 93.

Fernandes, C. M. da S. (2010, May 31). Análise das reconstruções faciais forenses digitais caracterizadas utilizando padrões de medidas lineares de tecidos moles da face de brasileiros e estrangeiros. Teses.usp.br. https://teses.usp.br/teses/disponiveis/23/23148/tde-03072010-103917/pt-br.php

Genival Veloso De França. (2008). Fundamentos de medicina legal. Guanabara Koogan. $8^{\mathrm{a}}$ ed. p. 640.

Herrera, L. M. (2015). Reconstrução facial forense: comparação entre tabelas de espessuras de tecidos moles faciais. Www.teses.usp.br. https://www.teses.usp.br/teses/disponiveis/23/23153/tde-21052016-100124/pt-br.php

Jorge Paulete Vanrell, \& De, M. (2007). Vademecum de medicina legal e odontologia legal. Jh Mizuno. P. 45.

Matos, R. A. et al. (2013). Reconstrução Facial Forense: indicações e métodos. Revista de Odontologia da UNESP, v. 41, n. Especial 2, p. 0-0. 
Paiva, L. A. S. de, Melani, R. F. H., \& Oliveira, S. V. T. (2005). Identificação humana através da sobreposição de imagens. Saúde Ética \& Justiça, 10(1-2), 15. https://doi.org/10.11606/issn.2317-2770.v10i1-2p1-5

Pereira, A. C. L., Woitchunas, C. A., Oliveira, F. A. M., Woitchunas, G. F. P., Oliveira, M. G. de, \& Santos, S. M. de M. C. dos. (2007). Cefalometria computadorizada de Ricketts: estudo comparativo, inter-raças e gêneros de indivíduos com harmonia facial. Ortodontia, 40(1), 1118.http://bases.bireme.br/cgibin/wxislind.exe/iah/online/?IsisScript=iah/iah.xis\&src=google\&base=LILACS\&lang=p\&nextAction=lnk\&exprSearch=542763\& indexSearch=ID

Pereira, J. G. D., Magalhães, L. V., Costa, P. B., \& Silva, R. H. A. da. (2017). Reconstrução facial forense tridimensional: técnica manual vs. Técnica digital. Revista Brasileira de Odontologia Legal, 46-54. https://doi.org/10.21117/rbol.v4i2.111

Queiroz, C. L. et al. (2017) A forensic identification case and DPid-can it be a useful tool?. Journal of Applied Oral Science, v. 25 , p. $346-353$.

Rocha, S. dos S., Ramos, D. L. de P., \& Cavalcanti, M. de G. P. (2003). Applicability of 3D-CT facial reconstruction for forensic individual identification. Pesquisa Odontológica Brasileira, 17(1), 24-28. https://doi.org/10.1590/s1517-74912003000100005

Schall, J. L., Rogers, T. L., \& Deschamps - Braly, J.C. (2020). Breaking the binary: The identification of trans - women in forensic anthropology. Forensic Science International, 309, 110220.

Shahrom, A. W., Vanezis, P., Chapman, R. C., Gonzales, A., Blenkinsop, C., \& Rossi, M. L. (1996). Techniques in facial identification: Computer-aided facial reconstruction using a laser scanner and video superimposition. International Journal of Legal Medicine, 108(4), 194-200. https://doi.org/10.1007/bf01369791

Silva, A. A.(2006). Crescimento e desenvolvimento craniofacial. São Paulo: Ed. Santos; p.153 - 5.

Simpson, E., \& Henneberg, M. (2002). Variation in soft-tissue thicknesses on the human face and their relation to craniometric dimensions. American Journal of Physical Anthropology, 118(2), 121-133. https://doi.org/10.1002/ajpa.10073

Vandermeulen, D., Claes, P., Loeckx, D., De Greef, S., Willems, G., \& Suetens, P. (2006). Computerized craniofacial reconstruction using CT-derived implicit surface representations. Forensic Science International, 159, S164-S174. https://doi.org/10.1016/j.forsciint.2006.02.036

Vanrell, J. P. (2009). Identidade e identificação. In: VANRELL, Jorge Paulete. Odontologia Legal \& Antropologia Forense. Rio de Janeiro: Guanabara

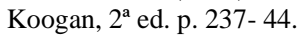

Velho, J. A., Geiser, G. C., Espíndula, A. (2013). Odontologia Legal. In: VELHO, Jesus Antonio. Ciências forenses. Uma Introdução às principais áreas da Criminalística Moderna, v. 2. p. 78-79.

Whittaker, David K. (1994). An introduction to forensic dentistry. Quintessence International, v. 25, n. 10: $723-730$. 